\title{
THE ALBERTA HIGH SCHOOL MATHEMATICS PROGRAM
}

Alberta high schools (Grades 10 to 12) give several courses in Mathematics, of which three are compulsory for those students intending to enter University. These three are Mathematics 10 (elements of Euclidean geometry, algebra up to simple equations, arithmetic), Mathematics 20 (geometry of the circle, loci, algebra up to quadratic equations) and Mathematics.30 (algebra, including systems of equations, progressions, permutations and combinations and the binomial theorem). In addition, a fourth course in Grade 12, Mathematics 31 (trigonometry and analytical geometry) is now required for students wishing to enter the Faculty of Engineering, or to embark on Physical Science programs (Mathematics, Physics, Chemistry, Geology) in the Faculty of Arts and Science.

The scope and content of Mathematics 10, 20, and 30 may be judged from the textbooks: "Mathematics for Canadians, Books 2 and 3", by Bowers, Miller and Rourke, and "An Advanced Course in Algebra" by Miller and Rourke. Certain of the more difficult sections and chapters are omitted in the courses as given.

Mathematics 31 is now a full-length 5-credit course, but without a departmental examination. A teacher's rating of $B$ or better is accepted as satisfactory. It is proposed to revise this course by cutting out most of the analytical geometry but doing the trigonometry more thoroughly. This should allow the University to dispense with trigonometry altogether in Freshman Mathematics and spend more time on calculus and analytical geometry.

There are always students in Arts and Science, and even some in Engineering, who want to take mathematics at the University but who do not present credit in Mathematics 31. For these students a special course with an extra hour of trigonometry has been provided.

This year the Mathematics Department of the University again conducted a special scholarship examination throughout the high schools. The paper was a three-hour one, written at the time of the regular departmental examinations. There were some 200 entries, of whom six received scholarships ranging in value from $\$ 500$ to $\$ 250$. The winners are all studying at the University of Alberta, although some of the scholarships (donated by the Congress) are tenable elsewhere. Although no candidate was really outstanding, the level of performance by the winners was quite respectable.

The University of Alberta, with help from the Canadian Mathematical Congress and from the Alberta Department of Education, is organizing a Summer Institute for Modern Mathematics in 1959, intended for high school teachers of mathematics throughout the Province, and indeed from neighbouring Provinces. 
Dr. Richard Andree from Oklahoma (author of "Selections from Modern Abstract Algebra") will give a course using this book, and Dr. Max Wyman will give one on "Elementary Mathematics from an Advanced Viewpoint". The courses will run for six weeks, concurrently with the regular Summer Session. Fund from the University, the Congress and the Department of Education are being used to provide bursaries which it is hoped will encourage teachers to attend. The bursaries will be worth $\$ 300$ to teachers outside Edmonton, or $\$ 200$ to those living in Edmonton, out of which they will pay the summer school fees and their board and lodging. The Institute will be under my general direction and I shall be glad to supply further information if it is desired.

The general purpose of the Institute is to acquant high school teachers with some of the more modern ideas that are beginning to percolate down to the first-year University level and that probably will find their way eventually even into high school. As a preliminary to a radical revision of the mathematics high school curriculum, it will be necessary to educate the teachers themselves, and the proposed Summer Institute is a step in this direction.

\section{E.S. Keeping}

\section{NEWS FROM THE DEPARTMENTS}

University of Alberta: Dr. W.J. Bruce from the Oregon College of Education, has been appointed to the staff. Mr. A. S. B. Holland, from New Zealand, has been appointed as a lecturer in the Calgary branch of the University.

Miss Z.M. Hyduk has been awarded the degree of M.Sc. for a thesis on "The Method of Darboux" (for Asymptotic Expansions). This work was done under the direction of Dr. M. Wyman.

Dr. Wyman gave a paper on "The Asymptotic Behavior of the Laurent Coefficients"at a Symposium on Asymptotic Expansions held in November at Pomona College, Claremont, California. On his way to California, Dr. W yman stopped off at Vancouver to give a mathematics talk at U.B.C.

For the first time for several years, the Department has entered a team in the Putnam Competition.

Assumption University of Windsor: This year the third year of the honours course in pure and applied Mathematics was introduced. The enrollment in the first three years of this course is fifteen.

Five graduates of the Mathematics major program returned for the extra year after graduation, required for specialist stand- 